\title{
PENERAPAN METODE PENCARIAN SEMANTIK DALAM SISTEM INFORMASI PENCARIAN DOKUMEN KERJA PRAKTEK DAN SKRIPSI BERBASIS WEB
}

\author{
${ }^{1)}$ Mitra Unik, ${ }^{2)}$ Muhammad Ramli \\ 1,2) Program Studi Teknik Informatika, Fakultas Ilmu Komputer, Universitas Muhammadiyah Riau \\ ${ }^{1,2)}$ Jl. KH. Ahmad Dahlan No.88, Sukajadi \\ E-Mail : mitraunik@umri.ac.id
}

\begin{abstract}
ABSTRAK
Penulisan ini membahas tentang pembuatan aplikasi pencarian dokumen kerja praktek dan skripsi di jurusan Teknik Informatika Fakultas Ilmu Komputer Univestias Muhammadiyah Riau. Aplikasi yang berbasis web ini menggunakan metode semantic search dalam hasil pencariannya. Aplikasi ini dirancang untuk menghasilkan pencarian kata yang relevan atau mudah dimengerti oleh mahasiswa dan juga menghasilkan kata yang terkait dengan kata kunci pencarian. Tujuannya adalah untuk mempermudah mahasiswa dalam mencari referensi dokumen kerja praktek dan skripsi serta untuk menghindari kesamaan topik dengan mahasiswa sebelumnya.
\end{abstract}

Kata Kunci: Pencarian Semantik, pencarian dokumen, sistem

\section{ABSTRACT}

This writing discusses the making of the application search documents practical work and thesis in the Department of Informatics Engineering Faculty of Computer Science Univestias Muhammadiyah Riau. This web-based application uses semantic search method in its search results. This app is designed to generate relevant or easy-to-understand search words by students and also generate words related to search keywords. The goal is to facilitate students in finding reference documents working practice and thesis and to avoid similarity with the previous student topic.

Key Word: semantic search, Document search, system

\section{PENDAHULUAN}

Permasalahan pencarian merupakan permasalahan yang sering muncul ketika hasil pencarian yang dihasilkan tidak sesuai dengan yang diinginkan. Beragam mesin pencari terus bersaing untuk memenuhi kebutuhan masyarakat akan perolehan informasi secara tepat dan cepat (Sarno, et al. 2012). Metode yang sesuai untuk membuat sistem pencarian yang berdasarkan kata kunci adalah metode semantic search. Semantic search berarti pencarian dokumen bukan hanya berdasarkan kata kunci saja namun juga makna yang terkait dengan kata kunci tersebut. Dengan mengenali adanya keterkaitan (relasi) kata yang ingin dicari dengan kata yang ada dalam database maka hasil pencarian akan menghasilkan tidak hanya kata yang dicari tetapi juga kata-kata yang terkait dengan kata tersebut.

Pada saat ini di TI Fasilkom Universitas Muhammadiyah Riau terdapat masalah dalam pencarian dokumen kerja praktek dan skripsi mahasiswa sebelumnya, yaitu masih menggunakan sistem manual dalam pencarian arsip tersebut. akibatnya, sering terjadi kesamaan ataupun pengulangan topic TI Fasilkom UMRI. Untuk itulah penelitian ini dilakukan, penulis akan membuat sebuah sistem informasi berbasis web yang digunakan untuk pencarian dokumen kerja praktek dan skripsi mahasiswa yang menggunakan metode semantic search. Dengan tujuan agar mahasiswa mudah mengetahui topik apa saja yang sudah pernah dibuat sebelumnya. Dan yang paling penting adalah untuk menghindari terjadinya pengulangan topic kerja praktek dan skripsi oleh mahasiswa TI Fasilkom UMRI.

\section{Pencarian}

Pencarian adalah proses untuk menemukan suatu informasi yang kita butuhkan. Misalnya, kita ingin mencari sebuah kata didalam dokumen 
digital yang kita miliki. Kita dapat mencarinya dengan beberapa cara misalnya dengan cara yang paling lambat yaitu membaca dokumen tersebut secara perlahan agar lebih teliti dalam menemukan kata yang ingin kita cari. Atau dengan cara yang lebih cepat namun akan mengurangi ketelitian dalam menemukan kata yang kita cari dengan memanfaatkan fitur pencarian yang telah disediakan di komputer.

\section{Web Semantik}

Web semantik merupakan suatu kumpulan teknologi yang memungkinkan komputer dapat memahami arti dari suatu informasi berdasar pada metadata, yaitu informasi mengenai isi informasi tersebut. Adanya metadata, komputer diharapkan mampu secara otomatis membantu manusia mengartikan hasil proses informasi sehingga hasil pencarian informasi dapat lebih akurat Metode web semantik membantu terjadinya revolusi dalam hal penyampaian dan pemanfaatan informasi pada World Wide Web (WWW).

\section{Semantic Search}

Semantic atau dalam Bahasa Indonesia semantik, adalah ilmu tentang makna kata dan kalimat; pengetahuan mengenai seluk-beluk dan pergeseran arti kata; bagian struktur bahasa yang berhubungan dengan makna ungkapan atau struktur makna suatu wicara. Tujuan pencarian semantik adalah mencari konten yang sesuai dengan konteks yang diinginkan pengguna (Rahutomo, 2009).

Ada dua jenis pencarian semantik menurut (Pollock, J, T., 2009). Jenis yang pertama adalah pencarian semantik dengan memberikan hasil berupa navigasi. Pengguna menggunakan mesin pencari sebagai alat navigasi untuk mengarahkan ke dokumen yang diinginkan. Navigasi ini dapat berupa link. Jenis yang kedua adalah dengan memasukkan frase atau kalimat yang menunjukkan keinginan pengguna untuk mendapatkan informasi. Pada jenis yang kedua ini, pengguna akan mendapatkan keseluruhan dokumen yang akan memberikan informasi secara lengkap. Intinya, pencarian semantik memberikan saran bagi pengguna berdasarkan penarikan kesimpulan yang dilakukan oleh sistem berdasarkan batasan-batasan tertentu (Sarno, 2012).

\section{Perbedaan semantic search dengan semantic web}

Ada perbedaan yang cukup jelas diantara semantic search dengan semantic web. DiSilvestro (2013) menulis pada sebuah situs online bahwa semantic search adalah proses pengetikan sesuatu ke dalam sebuah mesin pencari dan kemudian mendapatkan hasil pencarian yang selain menghasilkan kata kunci yang dicari juga menghasilkan kata lain yang terkait. Sedangkan semantic web adalah satu set teknologi untuk mewakili, menyimpan, dan melakukan query terhadap suatu informasi.

Tujuan utama dari semantic search adalah untuk menyediakan dokumen web yang paling relevan kepada para pengguna sesuai dengan query yang mereka gunakan dengan menggunakan domain ontologi yang spesifik (Mustapha, 2010).

\section{Semantic search processing}

Pada prosesnya, semantic search melakukan pencarian dengan cara mencocokkan query yang tepat dan hubungannya diantara kata kunci dalam otologi. Karena user lebih suka hasil yang meliputi semua kata kunci (Lee, 2009). Semantic search meningkatkan metode information retrieval (IR) konvensional dengan melihat pada perspektif yang berbeda seperti, arti kata yang dapat diformalkan dan diproses pada mesin yang menggunakan bahasa ontology seperti RDF (Resource Description Framework) dan OWL (Ontology Web Language) (Wei, 2008).

\section{METODE}

\section{Alur Kerja Penelitian}

Untuk membantu dalam penyusunan penelitian ini, maka perlu adanya alur kerja yang jelas tahapan-tahapannya. Alur kerja ini merupakan langkah-langkah yang akan dilakukan dalam penyelesaian masalah yang akan dibahas. Dalam penelitian ini metode yang digunakan dalam pengembangan sistem adalah ADDIE model. Model ADDIE merupakan model desain pembelajaran / pelatihan yang bersifat generic menjadi pedoman, dalam membangun perangkat 
dan infrastruktur program pelatihan yang efektif, dinamis dan mendukung kinerja pelatihan itu sendiri. Model ADDIE ini menggunakan 5 tahap pengembangan yaitu Analyze (analisis), Design (desain), Development (pengembangan), Implement (implementasi), dan Evaluate (evaluasi). Tahap analisis (Analyze) pada metode ADDIE merupakan analisis kebutuhan. Tahap desain (Design) dikenal dengan istilah membuat rancangan (blue print). Tahap Pengembangan (Development) merupakan proses mewujudkan blue print atau desain menjadi kenyataan. Tahap Implementasi (Implement) merupakan langkah nyata untuk menerapkan aplikasi atau produk yang telah didesain sedemikian rupa pada tahap design. Tahap Evaluasi (Evaluate) dilakukan disetiap tahap. Evaluasi digunakan pada penelitian untuk mengetahui apakah produk pengembangan sudah valid diaplikasikan.

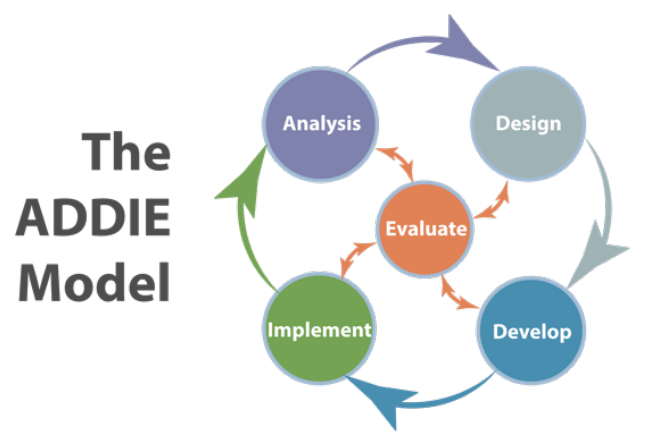

Gambar 1. Alur Kerja Penelitian ADDIE Model

\section{HASIL}

\section{Perancangan Proses}

Tujuan pembuatan sistem informasi pencarian yang menggunakan teknologi web semantic ini adalah untuk menghindari kesamaan atau pengulangan topic Kerja praktek dan Skripsi mahasiswa Fasilkom TI UMRI. Karena dengan sistem ini mahasiswa lebih mudah mengetahui judul atau topic apa saja yang sudah dibuat mahasiswa sebelumnya. Dan juga bisa juga untuk menjadi bahan referensi mahasiswa TI Fasilkom UMRI yang akan mengerjakan KP dan skripsi.

Perancangan aplikasi sistem yang akan dibuat adalah Usecase Diagrams, Activity Diagram, perancangan database dan perancangan halaman antar muka sistem. Berikut ini adalah tahapan- tahapan yang akan penulis lewati dengan pemodelan ini:

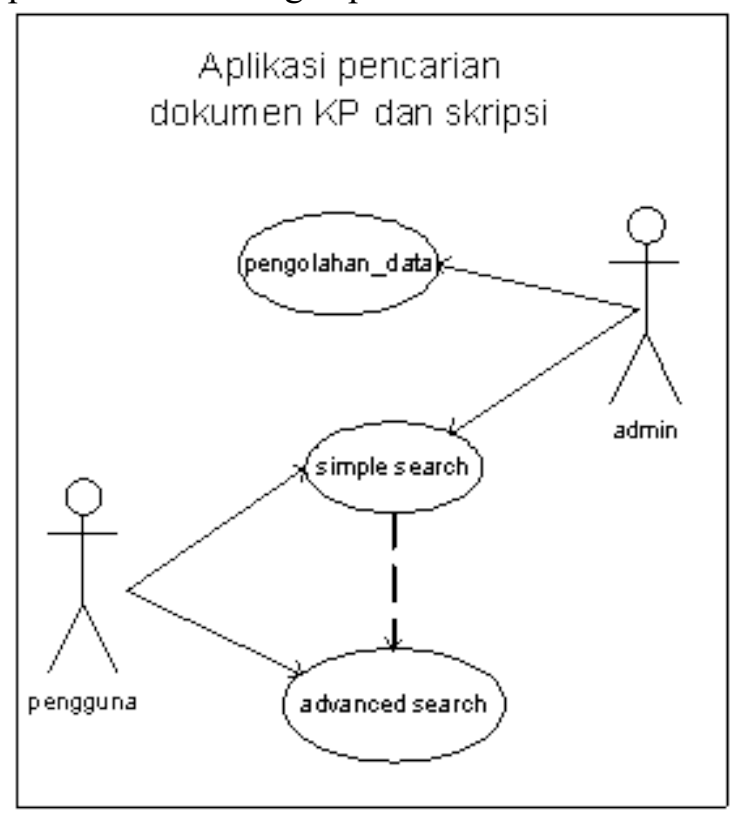

Gambar 2. Tahapan aplikasi

Perancangan antarmuka diperlukan untuk kenyamanan dalam mengakses web ini. Adapun rancangan antarmuka yang dibahas adalah perancangan antarmuka halaman depan, rancangan antarmuka output dan rancangan antarmuka input data.

Pada saat pertama kali mengakses sistem aplikasi maka akan ditampilkan halaman depan pengguna. Pada halaman ini terdapat form untuk melakukan pencarian. Dalam form terdapat field untuk memasukkan kata pencarian kemudian ada tombol search untuk melakukan pencarian. Rancangan halaman depan sistem dapat dilihat pada gambar dibaw Pada saat pertama kali mengakses sistem aplikasi maka akan ditampilkan halaman depan pengguna. Pada halaman ini terdapat form untuk melakukan pencarian. Dalam form terdapat field untuk memasukkan kata pencarian kemudian ada tombol search untuk melakukan pencarian. Rancangan halaman depan sistem dapat dilihat pada gambar dibawah ini. 


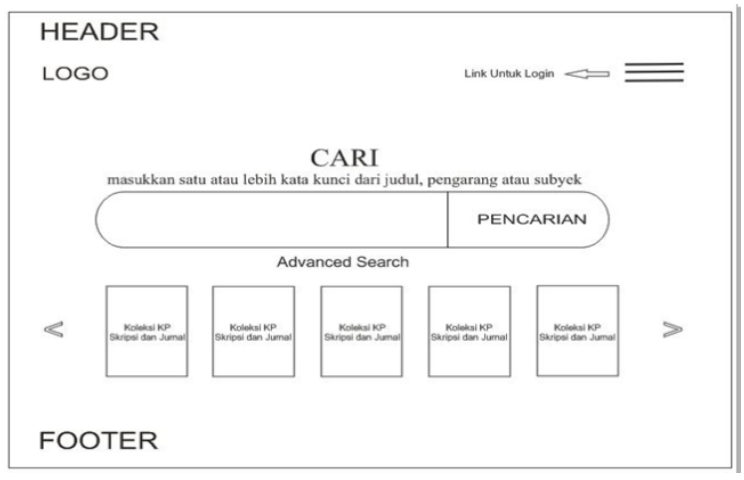

Gambar 3. Rancangan Halaman Depan aplikasi

Selain pengguna, sistem ini juga dapat diakses oleh admin sistem. Admin berfungsi sebagai penginput data judul KP dan skripsi. Pada rancangan halaman admin terdapat beberapa menu yaitu dashboard, e-jurnal, karya ilmiah, master file dan keluar. Dashboard merupakan halaman home admin, menu master file berfungsi untuk merubah atau menambah penulis, subyek, penerbit dan lokasi, menu e jurnal sama dengan halaman depan sistem. Selanjutnya pada menu karya ilmiah terdapat 2 pilihan, yang pertama untuk melihat daftar karya ilmiah dan yang kedua untuk menambah atau menginput data. Menu keluar untuk keluar dari login admin

\section{Implementasi}

1. Halaman Utama

Desain halaman utama sebagai tampilan awal dari Sistem untuk melakukan pencarian. User dapat mengetikkan keyword berdasarkan judul, penulis, abstrak serta subyek.

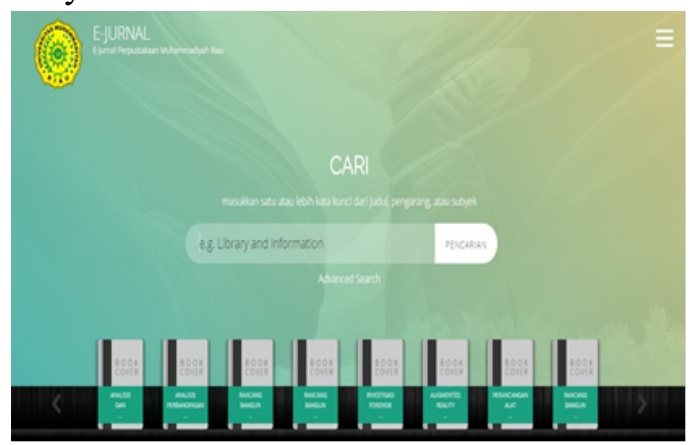

Gambar 4. Tampilan halaman depan untuk melakukan pencarian, masukkan kata kunci untuk melakukan pencarian. Sebagai contoh pencarian dengan kata kunci “ rancang bangun “

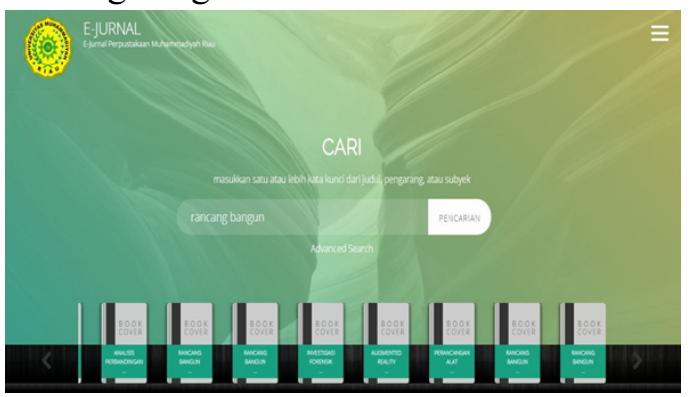

Gambar 5. Pencarian Kata Kunci Rancang Bangun

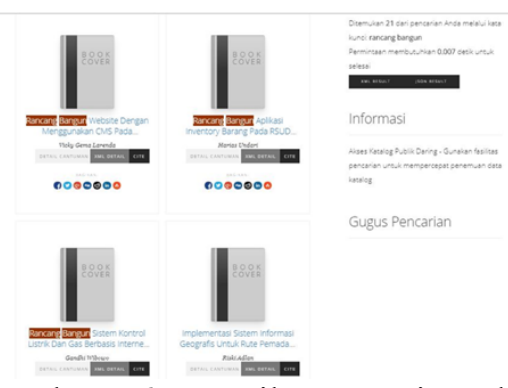

Gambar 6. Hasil pencarian kata kunci rancang bangun

3. Pencarian Advanced Search Berdasarkan Kategori

Sistem akan mencari pada menu advanced search seluruh laporan kerja praktek untuk memudahkan mahasiswa mencari referensi judul atau pembahasan laporan kerja praktek yang sudah diambil mahasiswa sebelumnya

4. Pencarian Berdasarkan Abstrak

Pencarian abstrak juga sangat penting, karena abstrak merupakan rangkuman dari isi tulisan dalam format yang sangat singkat dalam sebuah laporan skripsi. Berikut pencarian berdasarkan abstrak dengan kata kunci "Dalam usaha menjaga kestabilan suhu air kolam pembenihan maka rancang bangun sistem monitoring suhu air kolam dapat menjadi salah satu solusinya. “

2. Pencarian Simple search

Pada halaman awal sistem terdapat kolom 


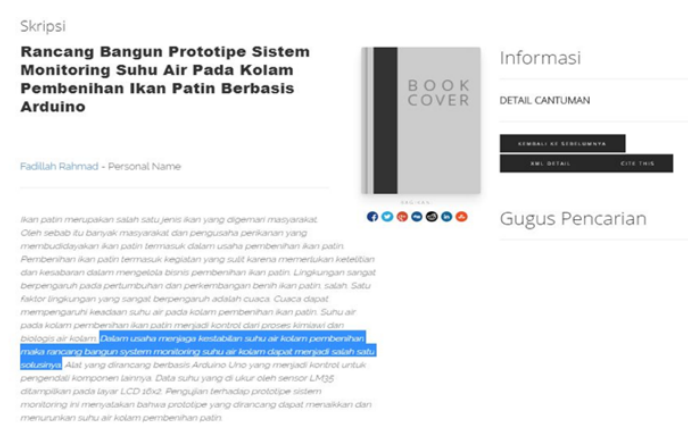

Gambar 5. Halaman berdasarkan abstrak

\section{KESIMPULAN}

Berikut ini merupakan kesimpulan dari proses perancangan, implementasi, dan uji coba terhadap sistem yang dibuat. Beberapa kesimpulan yang dapat diambil diantaranya:

1. Pencarian dengan metode semantic search terbukti mampu menghasilkan pencarian kata yang sesuai sekaligus menghasilkan kata lain yang terkait.

2. Dari relasi yang dibentuk, sistem dapat memberikan referensi kata kunci lain yang bertema sama dengan kata kunci yang diinputkan oleh Mahasiswa.

3. Metode Semantik Search mampu menandai kesamaman judul.

\section{DAFTAR PUSTAKA}

[1] Afuan, Mustofa. (2016). Penerapan SWRL ( Semantic Web Rule Languange) pada domain ontology universitas. Universitas Gadjah Mada

[2] Belia. (2014). Analisis Prosedur Pengembangan Model Addie dan $4 D$. Universitas Negeri Padang.

[3] Dwiono. (2013). Mesin pencari cerdas dengan web semantic. Universitas Sriwijaya

[4] Ferdilla, Mustikasari. (2011). Apllikasi web semantic untuk pencarian materi perkuliahan. Universitas Gunadarma Depok

[5] Frisnanto. (2010). Pembuatan aplikasi ensklopedia makanan tradisional berbasis web semantic. Institut Teknologi Sepuluh November

[6] Handayani, Yuhanan. (2009). Penerapan travel planning dan context - aware information service berbasis web semantic untuk system pariwisata di Indonesia. Fakultas Tekonlogi Informasi, Institut Teknologi Sepuluh November

[7] Rifki. ( 2014 ). Penerapan Metode Semantic Search Dalam Mencari Relasi Kata Yang Terdapat Pada Al - Qur'an Terjemahan Bahasa Indonesia. Fakultas Ilmu Komputer dan Teknologi Informasi Universitas Sumatera Utara, Medan

[8] Santosa. (2017). Pyle : Aplikasi ECommerce Berbasis Web Menggunakan Sistem Informasi Geografis. Universitas Pendidikan Ganesha Singaraja, Bali.

[9] Santoso, Herdiansyah, Syaputra. (2015). Penerapan web semantic dalam pencarian E-Arsip ijazah pada SDN 3 Sungai Rotan. Universitas Bina Darma Palembang

[10] Wijayanto. (2012). Penerapan web semantic dalam pencarian catalog buku di perpustakaan STMIK Nusantara Sinar Nusantara Surakarta. Sekolah Tinggi Manajemen Informatika dan Komputer Sinar Nusantara Surakarta

[11] Zebua, Mustikasari. (2011). Aplikasi pencarian buku berbasis web semantic untuk perpustakaan SMK Yadika $7 \quad$ Bogor.Universitas Gunadarma 